\title{
OPTIC DISC EDEMA/PAPILLEDEMA: A CLINICAL PROFILE
}

\author{
Deepshikha Solanki', Vandana Meena², Unnati Sharma3 ${ }^{3}$ Sanjeev Agrawal \\ ${ }^{1}$ Senior Resident, Regional Institute of Ophthalmology, Gandhi Medical College, Bhopal. \\ 2 Medical Officer, Regional Institute of Ophthalmology, Gandhi Medical College, Bhopal. \\ 3 Junior Resident, Regional Institute of Ophthalmology, Gandhi Medical College, Bhopal. \\ 4 Professor, Regional Institute of Ophthalmology, Gandhi Medical College, Hamidia Hospital, Bhopal.
}

\section{ABSTRACT}

\section{AIM}

To evaluate the clinical profile of patients with disc edema/papilloedema and its pattern in various patients.

\section{PURPOSE}

To evaluate causes of Disc edema/Papilloedema and associated clinical picture.

\section{DESIGN}

Prospective Study.

\section{METHOD}

This study is a non-randomized prospective case series being conducted in the patients with disc edema attending OPD and referred from other departments to RIO, Gandhi Medical College and associated Hamidia Hospital, Bhopal from Jan 2013-Sept 2014. Detailed history was taken with special preference to diminution of vision, headache, nausea, vomiting, sensory motor deficits experienced by patient. Examination including visual acuity, pupillary reaction and ophthalmoscopy findings were noted. Findings of neuroimaging investigations as advised by medicine and surgery experts in cases suspected of raised intracranial tension were noted.

\section{RESULTS}

Most commonly affected age group was 11-20 years. Females: Males ratio were 4.1:3 with bilateral predominance. Intracranial Space Occupying Lesion (ICSOL) was most common cause of papilledema in bilateral (b/l) cases. Optic neuropathy was most common local cause of unilateral disc edema. Headache was the most common presenting complaint. On radiological investigations, most common finding was ICSOL followed by sinusitis followed by venous thrombosis, demyelination and infarction, Lateral Rectus (LR) palsy and diplopia each were found to be present in $4 \%$ cases of disc edema.

\section{CONCLUSION}

Intracranial space occupying lesions as suggested by neuroimaging were the most common cause of papilledema. Other associations included hypertension, meningitis, pseudotumor cerebri, anaemia.

The study emphasizes ophthalmoscopy in the diagnosis of papilledema and its importance in intervention of neurosurgeon in saving life and sight of person.

\section{KEYWORDS}

Papilledema, Edema of Disc.

HOW TO CITE THIS ARTICLE: Solanki D, Meena V, Sharma U, et al. Optic disc edema/papilledema: a clinical profile. J. Evolution Med. Dent. Sci. 2016;5(16):795-800, DOI: 10.14260/jemds/2016/184

\section{INTRODUCTION}

Papilledema is a term introduced by Parson to indicate passive edema of the optic disc associated with Increased Intracranial Pressure (IICP). ${ }^{1}$ Optic nerve swelling from etiology other than IICP is known as optic disc edema. Causes include congenital arteriovenous aneurysm, cerebral tumor, spinal cord tumor, pseudotumour cerebri, congenital hydrocephalus with trauma, subdural hematoma, subarachnoid hemorrhage, vascular hypertension, albuminuric retinitis, inflammatory meningeal and cerebral involvement with orbital involvement with ocular involvement with sinusitis and in blood dyscrasias. ${ }^{2}$ relatively common cause of papilloedema is

Financial or Other, Competing Interest: None.

Submission 13-01-2016, Peer Review 08-02-2016,

Acceptance 15-02-2016, Published 25-02-2016.

Corresponding Author:

Dr. Deepshikha Solanki,

C/o., Mr. Chandrashekhar Solanki,

D-21, Char Imli, Bhopal-462016,

Madhya Pradesh.

E-mail: drdeepshikha.eyes@gmail.com

DOI: $10.14260 /$ jemds/2016/184 increased intracranial hypertension. ${ }^{3}$ Papilloedema may be observed at almost any age. ${ }^{4}$ most cases of papilledema are bilateral. ${ }^{5}$ the optic nerve head appearance can be asymmetric. Papilledema is relatively uncommon in infant due to lack of fusion of skull bone. Any reported unilateral papilledema should be observed and examined thoroughly.

\section{MATERIAL AND METHOD}

The present study is a non-randomized prospective case series being conducted in the patients with disc oedema/ papilloedema attending OPD and referred from other Departments to Regional Institute of Ophthalmology (RIO), Gandhi Medical College and associated Hamidia Hospital, Bhopal, from Jan 2013-Sept 2014.

\section{Inclusion Criteria}

Patients with disc oedema/papilloedema.

\section{Exclusion Criteria}

Patients with no disc oedema/papilloedema.

All the patients were evaluated with special reference to: 
1. Detailed personal history including name of patient, age, sex, address, socioeconomic status.

Symptoms including headache, nausea, vomiting, altered consciousness associated with duration of symptoms, Other risk factors like head injury, brain tumor, ocular infection, past history of ocular infection, surgery, trauma, drug history, recent relevant test report with date.

2. Thorough ophthalmic examination including:

a) Assessment of visual acuity on Snellen's chart and near vision.

b) Relative afferent pupillary defect-by swing flash light examination.

c) Colour vision is done by Ishihara's chart.

3. Intra ocular pressure-recorded with Schiotz indentation tonometer.

4. Slit lamp examination.

5. Optic disc evaluation: Using +78D/+90D Condensing lens, Following details were noted:

DISC, Cup size, Color of the disc, Cup:Disc ratio, Cup disc asymmetry between two eyes, Blurring of the disc margins, Hemorrhage over disc, Tortuosity of vein, Venous pulsation-in normal eye venous pulsation is present, if it is absent and not appear on pressing the globe it is indication of papilledema.

6. Fundus evaluation with indirect ophthalmoscope and +90 D slit lamp examination.

7. Investigations include blood, serum lipid profile, thyroid test, CSF, chest X-ray in specific cases.

8. General examination.

9. Neurology reference-In Neurosurgery Department, Hamidia Hospital, G.M.C. Bhopal.

10. MRI and CT Scan- It is done in Radiology Department, GMC, Bhopal.

11. Lumbar puncture-to check opening pressure as well as CSF biochemistry and microbiology. A thorough examination of patient was done at the time of presentation to obtain a baseline data against, which further papilledema and followup examination was compared with.

12. Fundus photography

Significant number of cases of raised ICP are primarily diagnosed on the basis of ophthalmoscopic finding of papilloedema and then confirmed by other investigations. In the present study, we will be evaluating the clinical profile of the patients of disc edema with special reference to Papilledema to highlight the role and significance of fundus evaluation at various stages and its clinical correlation.

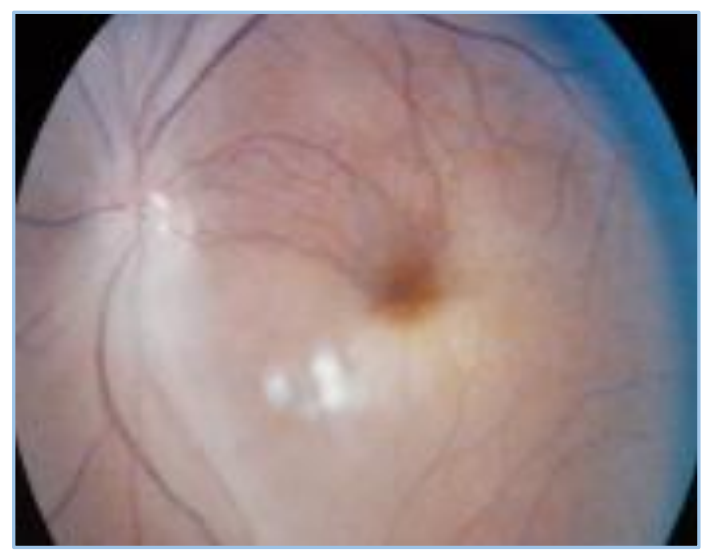

Fig. 1: BRAO showing Disc Edema

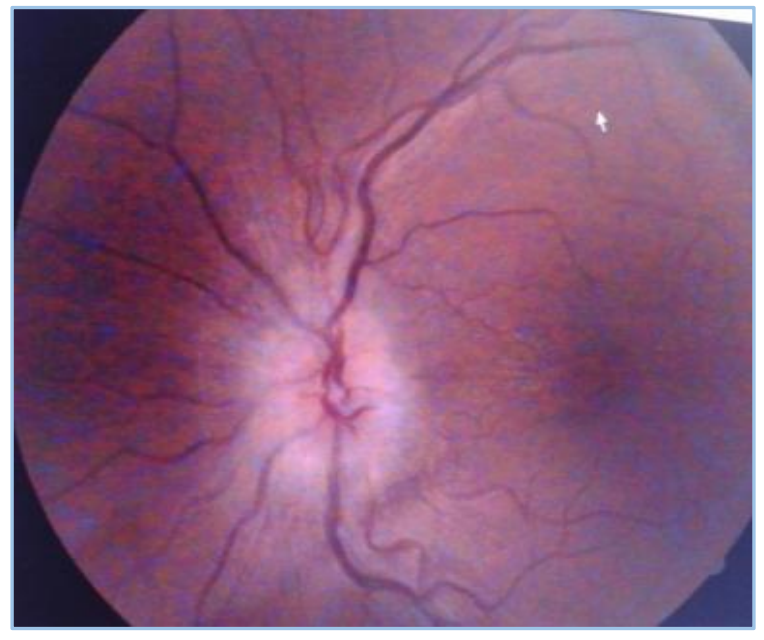

Fig. 2: Papilledema due to Superior sagittal sinus thrombosis

\section{OBSERVATIONS}

\begin{tabular}{|c|c|c|}
\hline $\begin{array}{c}\text { Age } \\
\text { (yr.) }\end{array}$ & $\begin{array}{c}\text { No. of } \\
\text { Patient } \\
\text { (n=50) }\end{array}$ & $\begin{array}{c}\text { \% of } \\
\text { Patient }\end{array}$ \\
\hline $0-10$ & 06 & 12 \\
\hline $11-20$ & 12 & 24 \\
\hline $21-30$ & 16 & 32 \\
\hline $31-40$ & 8 & 16 \\
\hline $41-50$ & 5 & 10 \\
\hline $51-60$ & 3 & 6 \\
\hline T0TAL Table 1: Age \\
\hline \multicolumn{2}{|c}{} \\
\hline \multicolumn{2}{|c}{} \\
\hline
\end{tabular}

Most commonly affected age group was between 21-30 years in which $32 \%$ case are observed, least common affected age group was 51-60 yr. in which 6\% cases are observed.

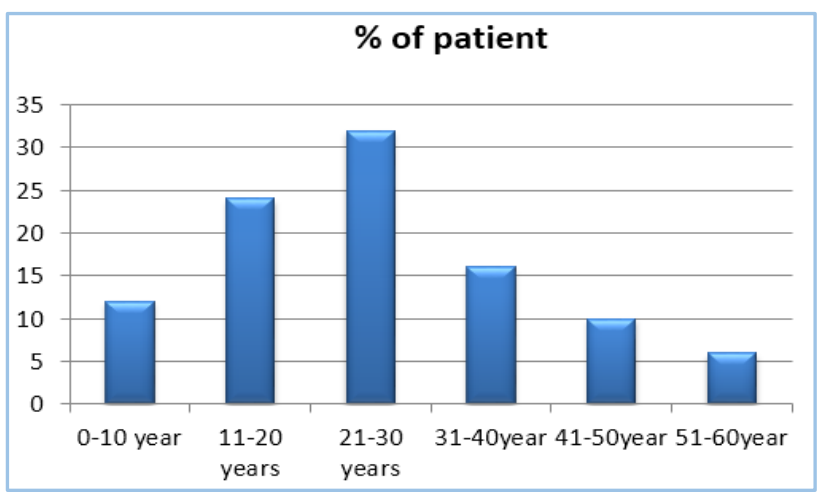

\begin{tabular}{|c|c|c|}
\hline Sex & $\begin{array}{c}\text { No. of Cases } \\
(\mathbf{n = 5 0})\end{array}$ & \% of Cases \\
\hline MALE & 21 & 42 \\
\hline FEMALE & 29 & 58 \\
\hline TOTAL & $\mathbf{5 0}$ & $\mathbf{1 0 0}$ \\
\hline \multicolumn{3}{|c|}{ Table 2: Sex } \\
\hline
\end{tabular}

In this study, $42 \%$ affected were males and $58 \%$ females. 


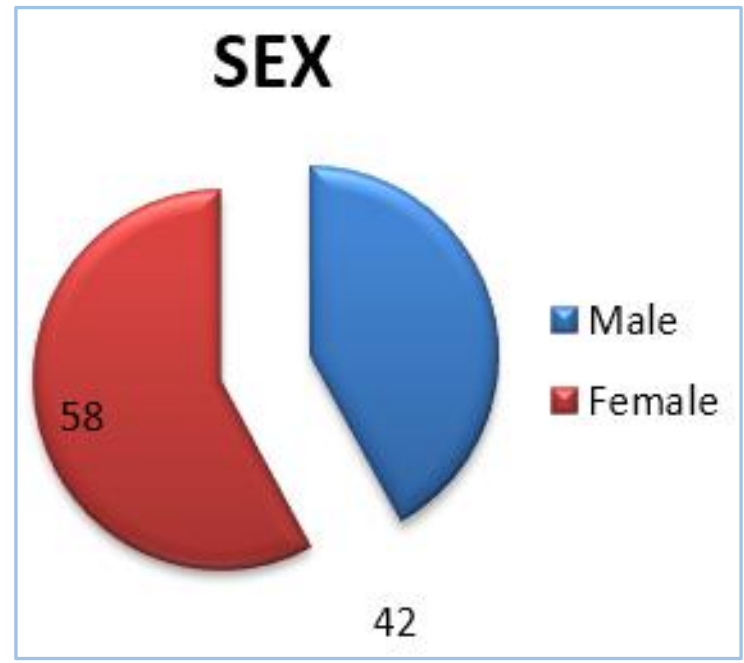

\begin{tabular}{|c|c|c|}
\hline $\begin{array}{c}\text { Laterality of } \\
\text { Disc Edema }\end{array}$ & $\begin{array}{c}\text { No. of } \\
\text { Case }(\mathbf{n = 5 0})\end{array}$ & $\begin{array}{c}\text { \% } \\
\text { of Case }\end{array}$ \\
\hline UNILATERAL & 15 & 30 \\
\hline BILATERAL & 35 & 70 \\
\hline TOTAL & $\mathbf{5 0}$ & $\mathbf{1 0 0}$ \\
\hline \multicolumn{3}{|c|}{ Table 3: Laterality } \\
\hline
\end{tabular}

In this study, $70 \%$ case of bilateral (Papilloedema) and $30 \%$ case of unilateral disc edema were observed.

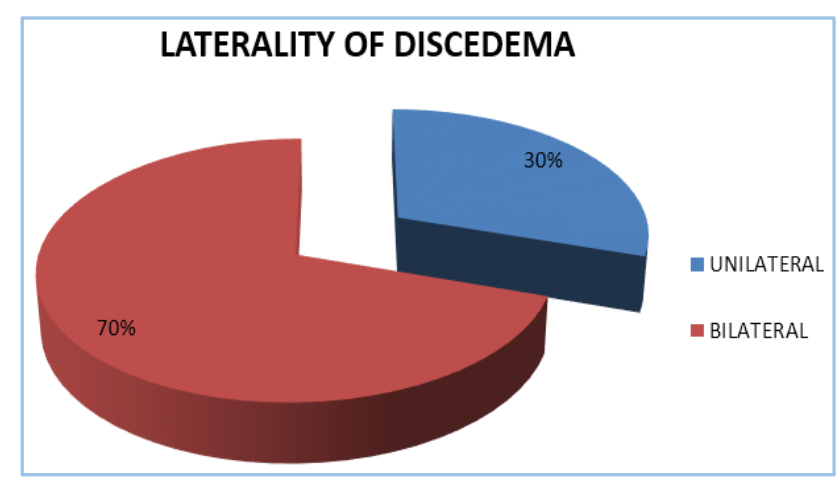

\begin{tabular}{|c|c|c|c|}
\hline \multirow{4}{*}{$\begin{array}{c}\text { LOCAL } \\
\text { CAUSES }\end{array}$} & $\begin{array}{c}\text { Causes } \\
\text { OPTIC }\end{array}$ & $\begin{array}{c}\text { No. of Cases } \\
\text { Cases }\end{array}$ \\
\cline { 2 - 4 } & AION & 3 & 22 \\
\cline { 2 - 4 } & BRAO & 1 & 6 \\
\cline { 2 - 4 } & HYPOTONY & 0 & 2 \\
\cline { 2 - 4 } & RAISED IOP & 0 & 0 \\
\hline \multicolumn{3}{|c|}{ TOTAL Table 4: Local Causes } \\
\hline \multicolumn{3}{|c|}{} \\
\hline
\end{tabular}

In this study out of 50 patients, $30 \%$ patients were of local cause in which $22 \%$ cases were of optic neuropathy followed by $6 \%$ cases of AION in age group of 51-60 year followed by $2 \%$ case of BRAO in age group of 41-50 year.

\begin{tabular}{|c|c|c|c|}
\hline \multirow{12}{*}{$\begin{array}{c}\text { SYSTEMIC } \\
\text { CAUSES }\end{array}$} & Causes & $\begin{array}{l}\text { No. of } \\
\text { Cases }\end{array}$ & $\begin{array}{l}\text { \% of } \\
\text { Cases }\end{array}$ \\
\hline & ICSOL & 12 & 24 \\
\hline & DIABETES & 1 & 2 \\
\hline & $\begin{array}{l}\text { MALIGNANT } \\
\text { HYPERTENSION }\end{array}$ & 5 & 10 \\
\hline & MENINGITIS & 6 & 12 \\
\hline & DRUG HISTORY & 4 & 8 \\
\hline & $\begin{array}{l}\text { PSEUDOTUMOR } \\
\text { CEREBRI }\end{array}$ & 1 & 2 \\
\hline & MALARIA & 3 & 6 \\
\hline & ANAEMIA & 1 & 2 \\
\hline & ENCEPHALOPATHY & 1 & 2 \\
\hline & HEAD INJURY & 1 & 2 \\
\hline & TOTAL & 35 & 70 \\
\hline \multicolumn{4}{|c|}{ Table 5: Systemic Causes } \\
\hline
\end{tabular}

In this study out of 50 patients, $24 \%$ cases of ICSOL in systemic causes followed by $12 \%$ cases of meningitis, $10 \%$ cases of malignant hypertension, $8 \%$ cases of drug history, $6 \%$ cases of malaria and $2 \%$ case each of diabetes, pseudotumor cerebri, anaemia, encephalopathy and head injury.

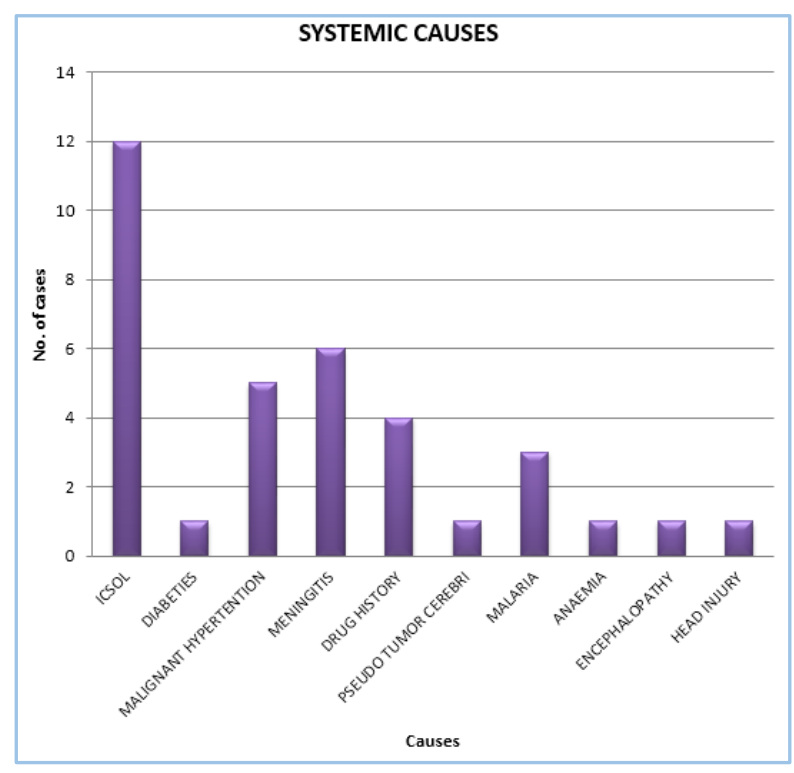

\begin{tabular}{|c|c|c|}
\hline Symptom & $\begin{array}{l}\text { No. of } \\
\text { Cases }\end{array}$ & $\begin{array}{l}\% \text { of } \\
\text { Cases }\end{array}$ \\
\hline Diminution of vision & 25 & 50 \\
\hline Headache & 35 & 70 \\
\hline Nausea/Vomiting & 24 & 48 \\
\hline $\begin{array}{c}\text { Transient obscuration of } \\
\text { vision }\end{array}$ & 8 & 16 \\
\hline Lateral Rectus Palsy & 2 & 4 \\
\hline Diplopia & 2 & 4 \\
\hline
\end{tabular}

Most common presenting complaint was headache in $70 \%$ cases followed by diminution of vision in $50 \%$ cases, nausea and vomiting in $48 \%$ cases, lateral rectus palsy and diplopia in $4 \%$ cases. 


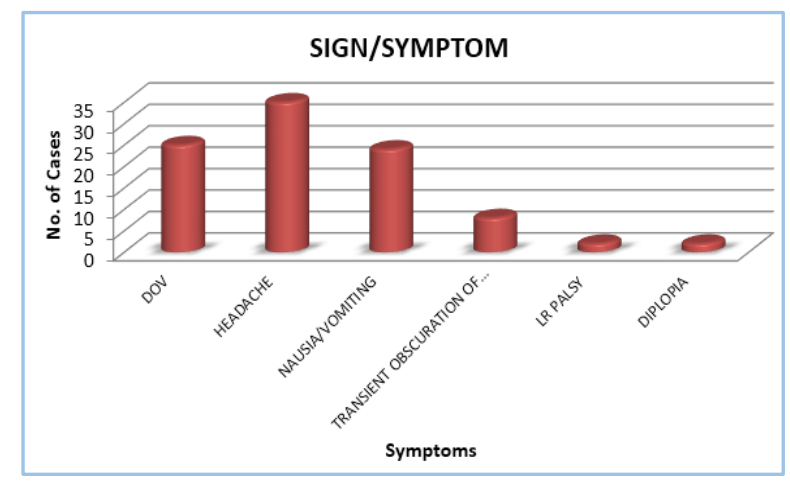

\begin{tabular}{|c|c|c|}
\hline Radiological Finding & No. of Cases & $\%$ of Cases \\
\hline ICSOL & 11 & 64.70 \\
\hline VENOUS THROMBOSIS & 2 & 11.76 \\
\hline DEMYELINATION & 1 & 5.88 \\
\hline SINUSITIS & 2 & 11.76 \\
\hline INFARCTION & 1 & 5.88 \\
\hline TOTAL & 17 & 100 \\
\hline \multicolumn{3}{|c|}{ logical Findi } \\
\hline
\end{tabular}

In radiological findings ICSOL observed in $70.58 \%$ cases followed by $11.76 \%$ cases of sinusitis followed by $5.88 \%$ case each venous thrombosis, demyelination and infarction.

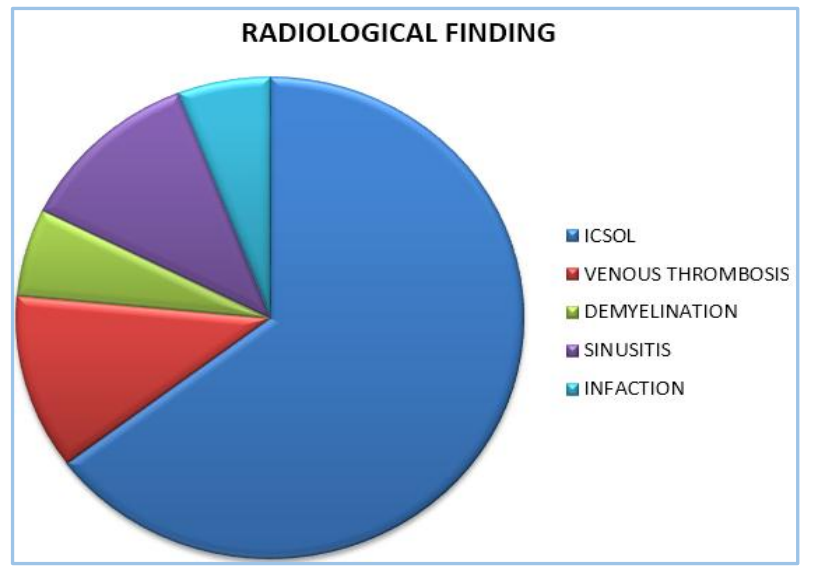

\section{DISCUSSION}

In this prospective non-interventional study we found following observation according to:

\section{Age and Sex}

Most commonly affected age group was between 21-30 years in which $32 \%$ cases are observed, followed by $24 \%$ cases were between age group of $11-20 y$ r. followed by $16 \%$ cases were between age group of $31-40 y$. followed by $12 \%$ cases were between age group of $0-10 \mathrm{yr}$. ; $10 \%$ cases between age group of $41-50 \mathrm{yr}$. and $6 \%$ in the age group of $51-60$ and least commonly affected age group was between 51-60 were $6 \%$ cases are observed.

In our study $42 \%$ affected were males and $58 \%$ females. The male:female ratio was 3:4.1. In this study we found papilledema in every age group. According to Frank B. Walsh. ${ }^{4}$ papilledema may be observed in any age.

\section{Laterality}

In this study $70 \%$ cases of bilateral. ${ }^{5}$ (papilloedema) and $30 \%$ cases of unilateral disc oedema were observed. Optic neuropathy, AION and BRAO accounted for unilateral cases of disc edema in this study.

ICSOL, meningitis, malignant hypertension, drug history, malaria, diabetes, pseudotumor cerebri, anaemia, encephalopathy and head injury accounted for bilateral cases of disc oedema/papilledema in this study.

\section{Local Causes}

In this study out of 50 patients, $30 \%$ patient were of local cause in which $22 \%$ cases were of optic neuropathy followed by $6 \%$ cases of AION in age group of 51-60 years followed by $2 \%$ cases of BRAO in age group of 41-50 years.

\section{Optic Neuropathy}

The most common age group affected was 11-20yr. (4 cases) and most common cause of optic neuropathy in this age group was maxillary sinusitis in 2 cases followed by one case each of optic nerve glioma, demyelination. This study coincides with study of A. Veselinovic et al. ${ }^{6}$ who reported optic neuritis in case of sinusitis.

This study coincide with the study of Rush JA, et al. ${ }^{7}$ who also found optic neuropathy in a case of optic nerve glioma in this age group in his study. Frank B. Walsh. ${ }^{8}$ states that optic neuritis (bilateral) may occur in demyelinating diseases. The second most common age group of optic neuropathy was 31$40 \mathrm{yr}$. ( 3 cases) and the cause of optic neuropathy was optic neuritis.

This study coincides with the study of Lee EK. ${ }^{9}$ et al. who also stated that the cause of optic neuritis is idiopathic in most of the case in this age group. The third most common age group of optic neuropathy were 21-30yr. (2 cases) and the cause of optic neuropathy was optic neuritis. The cause of optic neuropathy in age group of $0-10 \mathrm{yr}$. was optic neuritis due to viral fever.

\section{Aion}

The second most common local cause of optic disc edema was AION 6\% cases between age group of 50-60 years of age.

This study coincide with the study of Hattenhauer MG.10 et al which state that non-arteritic AION is commonly found above $50 \mathrm{yr}$. of age.

\section{Brao}

The third most common cause of optic disc edema is BRAO in $2 \%$ cases in age group of $41-50 \mathrm{yr}$.

\section{Systemic Causes}

In this study out of 50 patients, $24 \%$ cases of ICSOL in systemic causes followed by $12 \%$ cases of meningitis, $10 \%$ cases of malignant hypertension, $8 \%$ cases of drug history, $6 \%$ cases of malaria and $2 \%$ cases each of diabetes, pseudotumor cerebri, anaemia, encephalopathy and head injury.

\section{ICSOL}

Twelve cases of ICSOL are observed in this study in systemic causes; 4 each in age groups of 11-20yr., 21-30yr. and 31-40yr. The cause of ICSOL in the age group 11-20yr. was cerebellar neoplasm, frontal glioma, tuberculoma and choroid plexus papilloma. This study coincides with study of Patons.11 1909 who also found papilledema in cerebellar tumour and frontal tumour.

This study coincide with study of Kampherstein. ${ }^{12} 1905$ who found that a solitary tuberculoma produce papilledema. 
This study coincides with study of Gradin et al. ${ }^{13}$ who also found similar case of choroid plexus papilloma.

The causes of ICSOL in age group 21-30yr. were superior sagittal sinus thrombosis, neoplastic growth in brain, posterior fossa tumor, venous infarct in brain. This study coincides with study of Macken P. ${ }^{14}$ who reported two cases of superior sagittal sinus thrombosis having papilloedema.

This study coincide with study of Gowers. ${ }^{15}$ 1904According to him tumour (ICSOL) of the brain is the commonest cause and $80 \%$ of these are associated with the papilloedema. Most common cause of ICSOL in this age group 31-40yr. was meningioma, frontal lobe tumor, posterior fossa meningioma and cystic glioma involving fronto-parietal region. This study coincides with study of Patons. ${ }^{16} 1909$ who also found papilledema in similar case.

\section{Meningitis}

In this study, 4 cases of meningitis in age group 21-30 years were found in which papilledema were observed. This study coincides with study of Roh JK. ${ }^{17}$ who studied on TBM patient in age $15-73 y r$. and stated that $12 \%$ patient had papilledema. Two cases of meningitis in age group of $0-10 \mathrm{yr}$. were noted in which papilledema was observed. This study coincide with study of Levy J. ${ }^{18}$ who reported papilledema in similar case of meningitis.

\section{Malignant Hypertension}

In this study, 5 cases of MHT in age group of 21-30 yr. were observed. The cause of malignant hypertension in this age group (21-30yr.) is chronic renal failure in $3 / 5$ (60\%) and $2 / 5$ $(40 \%)$ cases are eclampsia (Toxemia of pregnancy).

This study coincides with study of Mary F. Schottstaedt.19 et al. who also found papilledema in MHT and toxemia of pregnancy.

\section{Drug History}

In this study, 1 case of drug history (Salicylate) was observed in age group 11-20yr. This study coincide with study of Greer et al. ${ }^{20} 1965$ who also said that use of salicylate may produce papilledema.

Two cases of drug history (Antidepressant, antipsychotic) were observed in age group 41-45yr. This study coincide with study of Blumberg and Klein.21 1961 also said that use of tranquilizer may cause papilledema. One case of drug history (Hypervitaminosis-A) was observed in age group 31-40yr.

One case of pseudotumor cerebri was observed in age group 21-30yr. having papilledema.

This study coincides with study of Brosh $\mathrm{K}$, et al. ${ }^{22}$ who also found a case of pseudotumor cerebri in this age group having papilledema.

\section{Head Injury}

One case of head injury in age group 31-40yr. was observed having papilledema.

This study coincides with study Dany, et al.23 1928 who also found similar case of head injury.

\section{Anaemia}

In systemic causes, 1 case of anaemia in age group 11-20yr. was observed having papilledema.

This study coincides with study of Biousse V, et al. ${ }^{24}$ who also found papilledema in anaemia.

\section{Malaria}

In systemic causes, 3 cases of malaria in age group 11-20yr. (2 cases) and 0-10yr. (1 cases) were observed.

This study coincide with study of Smith A, et al. ${ }^{25}$ who also found papilledema in patient suffering from malaria.

\section{Encephalitis}

One case of encephalitis in age group 0-10yr. was observed.

\section{Sign and Symptom}

In this study, Diminution of Vision (DOV) occur in $50 \%$ of cases. Majority of case DOV were due to local cause due to optic neuropathy, AION, BRAO. In systemic cause DOV were due to malignant hypertension, diabetes, ICSOL (Due to ICT Lead to papilledema. Visual loss generally does not occur in papilledema, visual loss only occurs in papilledema when optic atrophy start).

In this study headache occur in $70 \%$ of cases and mostly in patient with papilledema. Transient obscuration of vision in $16 \%$ of cases and lateral rectus palsy (Tubercular meningitis and optic nerve glioma) and diplopia (Tubercular meningitis and optic nerve glioma) in $4 \%$ of cases.

This study coincides with study of Schirmer CM.26 et al. in which state that Visual symptoms in papilledema can lead to permanent visual loss if left untreated.

This study coincide with study of Jackson. ${ }^{27}$ 1873Suggest that transient attack of blurring of vision or even blindness in papilledema is cortical in origin.

This study coincide with study of Leber. ${ }^{28} 1877$ - Suggest that transient attack of blurring of vision or even blindness in papilledema is due to sudden pressure from the third ventricle through the infundibulum upon the chiasma.

This study coincide with study of Harms. ${ }^{29}$ 1906-Suggest that transient attack of blurring of vision or even blindness in papilledema is due to temporary spasm of the retinal arteries. This study coincides with study of Paton. ${ }^{30}$ 1909- Gave opinion that premonitory attacks are commonest with cerebellar tumor suggest that pressure by an internal hydrocephalus may be responsible for transient blurring of vision.

This study coincides with study of Sergott RC. ${ }^{31}$ states that headaches associated with papilledema may be lifethreatening as well as vision-threatening. This study coincide with study of Roh JK.17 1983 who observed lateral rectus palsy in his study.

\section{Radiological Investigation}

In radiological study ICSOL is observed in $70.58 \%$ cases, followed by $11.76 \%$ cases of sinusitis followed by $5.88 \%$ cases each venous thrombosis, demyelination and infarction.

\section{Summary}

Observations can be summarized as under:

- Most commonly affected age group was between 21-30 years in which $32 \%$ cases.

- Least commonly affected age group were between age group of 51-60yr. in which $6 \%$ cases.

- $42 \%$ affected were males and $58 \%$ females. The male:female ratio was 3:4.1.

- In this study out of 50 patients, $30 \%$ patients of local cause and $70 \%$ cases were of systemic causes.

- Amongst local causes, most common cause was optic neuropathy in $22 \%$ cases. 
- Amongst systemic causes most common cause was ICSOL in $24 \%$ cases.

- In local causes, majority of cases of optic neuropathy in this age group 11-20yr. and causes were sinusitis followed by optic nerve glioma and demyelination each.

- The second most common local cause of optic disc oedema were AION 6\% cases between 50-60 years of age.

- The third most common local cause of optic disc oedema was BRAO in $2 \%$ cases in age group of $41-50 \mathrm{yr}$.

- In this study, $24 \%$ cases of ICSOL in systemic causes followed by $12 \%$ cases of meningitis followed by $10 \%$ cases of malignant hypertension followed by $8 \%$ cases of drug history followed by $6 \%$ cases of malaria followed by $2 \%$ cases of each diabetes, pseudotumor cerebri, anaemia, encephalopathy and head injury.

- Most common presenting complaint was headache in $70 \%$ cases followed by DOV in 50 \%cases, nausea and vomiting in $48 \%$ cases, LR palsy and Diplopia in $4 \%$ cases.

- In this study in radiological finding ICSOL is observed in $760.58 \%$ cases followed by $11.76 \%$ cases of sinusitis followed by $5.88 \%$ case each venous thrombosis, demyelination and infarction.

\section{CONCLUSION}

- Papilledema/disc oedema most commonly affected age group 11-20 years.

- Females outnumbered males in the ratio of 4.1:3.

- B/L cases were more common than U/L cases.

- Optic neuropathy accounted for most common local cause of unilateral disc oedema.

- ICSOL was most common systemic cause of papilledema.

- Headache was the most common presenting complaint.

- On radiological investigations, most common finding was ICSOL observed followed by sinusitis followed by venous thrombosis, demyelination and infarction.

- LR palsy and diplopia each were found in $4 \%$ cases of disc edema.

\section{BIBLIOGRAPHY}

1. Walsh FB, Hoyt WF. In Clinical Neuro-Ophthalmology (ed 2), Baltimore, page 276.

2. Walsh FB, Hoyt WF. In Clinical Neuro-Ophthalmology (ed 2), Baltimore, page 280.

3. Walsh FB, Hoyt WF. In Clinical Neuro-Ophthalmology (ed 2), Baltimore, page 280.

4. Walsh FB, Hoyt WF. In Clinical Neuro-Ophthalmology (ed 2), Baltimore, page 280 .

5. Duke-Elder S; Neuro-ophthalmology, volume 12, page 42.

6. Aleksandar Veselinovic, Maja Zivkovic, et al. Optic neuritis and sinusitis; Eur J Ophthalmol 2011; DOI:10.5301/EJ0.2011.7893.

7. Rush JA; Younge BR; Campbell RJ; MacCarty CS. Ophthalmology [1982;89(11):1213-1219].

8. Walsh FB, Hoyt WF. In Clinical Neuro-Ophthalmology (ed 2), Baltimore, page 306.
9. Lee EK; Jin KH; Kim SM. Disorder of the optic nerve; Age Group Unspecified; Optic Neuritis; Visual; Clinical Journal of the Korean Ophthalmological Society 1991;32(5):389-396.

10. Hattenhauer MG; Leavitt JA; Hodge DO; et al. American Journal of Ophthalmology [1997;123(1):103-107].

11. Duke-Elder S. Neuro-ophthalmology. In Duke-Elder (ed); volume 12, Paton's 1909, page 37.

12. Duke-Elder S. Neuro-ophthalmology. In Duke-Elder (ed); volume 12, Kampherstein 1905, page 38.

13. Wesley C Gradin, MD; Charles Taylon, MD; Alan H Fruin, MD. Choroid Plexus Papilloedema of the Third Ventricle, (Neurosurgery 12:217-220, 1983).

14. Macken P, Arora A, Hipwell G, et al. Superior sagittal sinus thrombosis- an unexpected cause of papilloedema. Aust N Z J Ophthalmol 1992 Nov; 20(4):337-42.

15. Duke-Elder S. Neuro-ophthalmology. In Duke-Elder (ed); volume 12, Gower 1904, page 37.

16. Duke-Elder S. Neuro-ophthalmology. In Duke-Elder (ed); volume 12, PATONS 1909, page 37.

17. Roh JK. Korean. A study on tuberculous meningitis in adults: with special reference to abnormal neurologic signs and prognosis. J Korean Neurol Assoc 1983 Dec; 1(2):21-30.

18. Levy J, Shneck M, Marcus M, et al. Brucella meningitis and papilledema in a child. Eur J Ophthalmol 2005 Nov-Dec; 15(6):818-20.

19. Mary F Schottstaedt, Maurice Sokolow. American Heart Journal; Volume 21(1), January 41, Pages 94-97.

20. Duke-Elder S. Neuro-ophthalmology. In Duke-Elder (ed); volume 12, Greer 1965, page 42.

21. Duke-Elder S; Neuro-ophthalmology. In Duke-Elder (ed); volume 12, Blumberg and Klein 1961, page 42.

22. Brosh K, Strassman I. Unilateral papilledema in pseudotumor cerebri. Semin Ophthalmol 2013 Jul; 28(4):242-3.

23. Duke-Elder S. Neuro-ophthalmology. In Duke-Elder (ed); volume 12, Dany 1928 Ford and Murphy 1939, page 39.

24. Biousse V, Rucker JC, Vignal C, et al. Anaemia and papilledema. Am J Ophthalmol 2003 Apr; 135(4):437-46.

25. Smith A, Beare NA, Musumba CO, et al. New classification of acute papilledema in children with severe malaria. J Pediatr Neurol 2009;7(4):381-388.

26. Schirmer CM, et al. Neurosurg Focus. Mechanisms of visual loss in papilledema 2007;23(5):E5.

27. Duke-Elder S. Neuro-ophthalmology. In Duke-Elder (ed); volume 12, Jackson 1873, page 58.

28. Duke-Elder S. Neuro-ophthalmology. In Duke-Elder (ed); volume 12, Leber 1877, page 59.

29. Duke-Elder S. Neuro-ophthalmology. In Duke-Elder (ed); volume 12, Harms 1906, page 59.

30. Duke-Elder S. Neuro-ophthalmology. In Duke-Elder (ed); volume 12, Paton 1909, page 59.

31. Sergott RC. Headaches associated with papilledema. Curr Pain Headache Rep 2012 Aug; 16(4):354-8. 